\title{
Swelling Behavior of poly (N-cyclohexylacrylamide -co- Acrylamide/ Maleic acid) Hydrogels
}

\author{
R. Chitra ${ }^{1}$, S. Anbarasan ${ }^{2}$, E.Kayalvizhy ${ }^{3} \&$ P.Pazhanisamy ${ }^{4 *}$ \\ ${ }^{1}$ Department of Chemistry, Guru Nanak College, Affiliated to University of Madras, Chennai \\ -600 042, Tamil Nadu, India. \\ ${ }^{2}$ Department of Chemistry, Thiru. A.Govindasamy Govt.Arts College, Affiliated to Thiruvalluvar \\ University, Tindivanum,-604307, TamilNadu, India \\ ${ }^{3}$ Department of Chemistry, PSGR Krishnammal College for Women, Coimbatore-641004, \\ Affiliated to Bharathiar University, India. \\ ${ }^{4}$ Department of Chemistry, Sir Theagaraya College, Affiliated to University of Madras, \\ Chennai-600 021, Tamil Nadu, India. \\ E-mail: p_pazhanisamy@yahoo.com
}

\begin{abstract}
In this study, a series of poly (N-cyclohexylacrylamide-co-Acrylamide/Maleic acid) hydrogels were prepared from free-radical copolymerization in water/methanol medium using ammonium persulfate (APS) as a free radical initiator and N,N'-methylene-bis-acryl amide $(M B A)$ as the cross-linker at $60^{\circ} \mathrm{C}$. The synthesized hydrogels were characterized by FTIR, SEM, XRD and TGA techniques. Swelling parameters in water and dye solution were calculated. The effect of two cationic salt solutions on the swelling was studied. The hydrogels showed up to $47.9 \%$ removal efficiency towards methylene blue dye adsorption study.
\end{abstract}

Keywords: Swelling behaviour, Maleic acid, Dye adsorption study, SEM analysis, Methylene blue.

\section{Introduction}

Hydrogels represent polymeric networks capable of absorbing large quantities of water, but remain insoluble due to chemical or physical crosslinks between individual polymeric chains [1]. When fully hydrated, can contain over $95 \%$ water, therefore they are in effect parcels of water that can be easily handled. Their ability to absorb water is due to the presence of hydrophilic groups such as $-\mathrm{OH},-\mathrm{CONH},-\mathrm{CONH}_{2},-\mathrm{COOH},-\mathrm{SO}_{3} \mathrm{H}$ etc. Hydrogels can be divided into two categories based on the chemical or physical nature of the crosslink junctions. Chemically crosslinked networks have permanent junctions, while physical networks have transient junctions that arise from either polymer chain entanglements or physical interactions such as ionic interactions, hydrogen bonds, or hydrophobic interactions They are also classified as non-ionic and ionic materials in which the ionic type comprises of anionic $\left(-\mathrm{CO}_{2}{ }^{-},-\mathrm{SO}_{3}{ }^{-}\right)$ or cationic pendants $\left(-\mathrm{NR}_{3}^{+}\right)$. Due to specific properties like swelling in water, biocompatibility, absorbing water easily or hydrophilicity, and non-toxicity, hydrogels can be 
used in various fields of biomedical, catalytic, optical, pharmaceutics and environment [2-4]. Recent trends demonstrate that the macroscopic gels are becoming most promising as templates/nano reactors for in situ synthesis of smaller size nanoparticles and this strategy has brought up a new concept in hybrid or composite systems in chemistry and engineering science [5-7]. A promising antimicrobial coating of Poly (2-hydroxylethyl acrylate) (PHEA) and Poly(ethylenimine) (PEI) networks loaded with Ag nanoparticles, modified with Poly(ehyleneglycol) (PEG) was reported for biomedical and daily-life applications [8].

In our previous paper [ 9], we reported Synthesis and Swelling behavior of Poly (N-tertamylacrylamide-co-Acrylamide/Maleic acid) Hydrogel. The aim of the present study is to synthesize a functional hydrogel to evaluate as an adsorbent for methylene blue dye. This has been achieved by terpolymerization of NCA, AM and MA in the presence of MBA and clay in methanol/water medium and its effectiveness as an anionic adsorbent for removal of dye has been investigated MB as model cationic dye.

\section{Experimental}

\section{Preparation of N-cyclohexylacrylamide (NCA)}

The monomer $\mathrm{N}$-cyclohexylacrylamide was prepared by the reaction of Cyclohexanol with acrylonitrile [10]. N-cyclohexylacrylamide was recrystallized in warm dry benzene. The white crystals have a m.p. $115^{\circ} \mathrm{C}$ and the yield was $87 \%$.

\section{Synthesis of Poly (N-cyclohexylacrylamide-co-acrylamide/Maleic acid) Hydrogels}

Free-radical crosslinking copolymerization was carried out in methanol /water mixture as the polymerization solvent, at $60^{\circ} \mathrm{C}$ in the presence of APS as initiator and MBA as crosslinker. Aqueous solution containing NCA (0.5g), AM (0.5g), MBA (0.050g), APS $(0.050 \mathrm{~g})$, MA $(0.050,0.100,0.150,0.200 \mathrm{~g})$ were prepared in methanol water mixture . After bubbling nitrogen for $15 \mathrm{~min}$, the contents were placed in thermostatic water bath at $60^{\circ} \mathrm{C}$ and the polymerization was conducted for 1 day. After the reaction, the hydrogels were cut into pieces 3-4 mm long. The extracted hydrogels were dried in vacuum oven at $50^{\circ} \mathrm{C}$ to constant weight for further use. Hydrogels feed compositions are mentioned in Table-1.

Table -1: Synthesis of Poly (N-cyclohexylacrylamide-co-acrylamide/Maleic acid) Hydrogels

\begin{tabular}{|c|c|c|c|c|c|c|}
\hline S. No & $\begin{array}{c}\text { Wt. of } \\
\text { NCA } \\
(g)\end{array}$ & $\begin{array}{l}\text { Wt. of } \\
\text { AM (g) }\end{array}$ & $\begin{array}{l}\text { Wt. of } \\
\text { MA (g) }\end{array}$ & $\begin{array}{c}\text { Wt.of APS } \\
\text { (g) }\end{array}$ & $\begin{array}{c}\text { Wt. of } \\
\text { MBA (g) }\end{array}$ & $\begin{array}{c}\text { Methanol/ } \\
\text { water (3:1) } \\
(\mathrm{ml})\end{array}$ \\
\hline 1 & 0.500 & 0.500 & 0.050 & 0.050 & 0.050 & 20 \\
\hline 2 & 0.500 & 0.500 & 0.100 & 0.050 & 0.050 & 20 \\
\hline 3 & 0.500 & 0.500 & 0.150 & 0.050 & 0.050 & 20 \\
\hline 4 & 0.500 & 0.500 & 0.200 & 0.050 & 0.050 & 20 \\
\hline
\end{tabular}




\section{Characterization of Hydrogels}

FT-IR Spectroscopy is an effective way to identify organic compounds or polymers with functional groups. For FT-IR measurements Nicolet Nexus-670 FTIR spectrophotometer was used. The hydrogels were dried in vacuum at $50^{\circ} \mathrm{C}$ for $48 \mathrm{hrs}$ till constant weight. The dried samples were embedded in $\mathrm{KBr}$ disks after being ground into powder. The scanning wave number ranged from 4000 to $500 \mathrm{~cm}^{-1}$. The surface morphology of the freeze-dried hydrogels was studied by Scanning Electron Microscopy. Hydrogels were performed using Hitach, model-JSM-5000 imaging mode at $30 \mathrm{kV}$ with varying levels of magnification. To prepare samples for SEM, the swollen hydrogels were freeze-dried and then sputter coated with gold. The X-ray diffraction studies of the hydrogels were carried out using a BRUKER diffractometer (Germany), model D8 Advance, employing rotting $\mathrm{Cu}$ anode. Thermo Gravimetric Analysis was used to investigate the thermal stability and crosslink densities of the prepared hydrogels. The TGA thermograms were recorded on a Perkin Elmer-7 at a heating rate of $10^{\circ} \mathrm{C} / \mathrm{min}$ under $\mathrm{N}_{2}$ protection over a temperature range from room temperature to $800^{\circ} \mathrm{C}$.

\section{Swelling behavior}

Swelling experiments were carried out with a view of evaluation the swelling capacity of the hydrogels under investigation in double distilled water. When a hydrogel is brought into contact with water, water diffuses and the hydrogel swells. The swelling behavior of the hydrogels was determined by applying in the following equation

$$
\text { Ds \% }=[(\mathbf{W s}-\mathrm{Wd} / \mathrm{Wd})] \mathbf{X} 100
$$

Where (Ds\%) is the degree of swelling most commonly described as swelling ratio which is expressed as increase in weight / gm of dried hydrogel after keeping in contact with water for selected period of time. Ws is the weight of the swollen gel at a given time and $\mathrm{Wd}$ is the weight of the dry gel.

\section{Effect of electrolytes}

Different concentrations of $\mathrm{NaCl}$ and $\mathrm{KCl}$ have been used to see the effect of electrolyte concentration on swelling of hydrogel.The swelling decreased as the concentration of $\mathrm{NaCl}$ and $\mathrm{KCl}$ increased in the solution. It was due to the fact that an increase of the ionic strength of the solution leads to a decrease in the swelling ratio of the hydrogels. In water, the hydrogel has maximum osmotic pressure, hence the maximum swelling. But when the hydrogel was placed in $\mathrm{NaCl}$ and $\mathrm{KCl}$ solutions, the osmotic pressure of ionic hydrogel is lower due to $\mathrm{Na}^{+}$, $\mathrm{K}^{+}$and $\mathrm{Cl}^{-}$ions.

\section{Adsorption of Methylene blue (spectrophotometer-106, systronics)}

A weighed quantity of dry hydrogel $(0.1 \mathrm{~g})$ was immersed in enough methylene blue $(25 \mathrm{ppm}, 20 \mathrm{ml})$ and kept at $37^{\circ} \mathrm{C}$.The amount of $\mathrm{MB}$ adsorbed was measured spectrophotometrically $(\lambda: 661.6 \mathrm{~nm})$ in periodically taken solution samples and again placed in the same vessel so that the liquid volume was kept constant. The adsorption capacity (Q) and removal efficiency (RE \%) of the dye by the hydrogel was calculated by using the following expression: 
(1) The adsorption capacity Q (mg dye per g polymer) of hydrogel was calculated by using the following expression:

$$
\mathbf{Q}(\mathbf{m g} / \mathrm{g})=\left(\mathbf{C}_{\mathbf{i}}-\mathbf{C}_{\mathbf{e}}\right) \mathrm{V} / \mathrm{m}
$$

Where $\mathrm{Ci}$ and $\mathrm{C}_{\mathrm{e}}$ are the initial and equilibrium concentrations of the dye in the solution, respectively $(\mathrm{mg} / \mathrm{l}), \mathrm{V}$ is the volume of the solution added (l) and $\mathrm{m}$ is the amount of hydrogel used (g)

(2) The Removal efficiency (RE \%) of hydrogels was calculated by using the following expression.

$$
\mathrm{RE} \%=\left(\mathrm{C}_{0}-\mathrm{C} / \mathrm{C}_{0}\right) \times 100
$$

Where $\mathrm{C}_{0}$ and $\mathrm{C}$ are the initial and equilibrium concentrations of the $\mathrm{MB}$ dye solution, respectively

\section{Results and Discussion}

\section{Synthesis and Characterization of Poly(N-cyclohexylacrylamide-co Acrylamide/Maleic} acid) Hydrogels

The schematic representation of Hydrogel preparation is shown in Figure -1 .
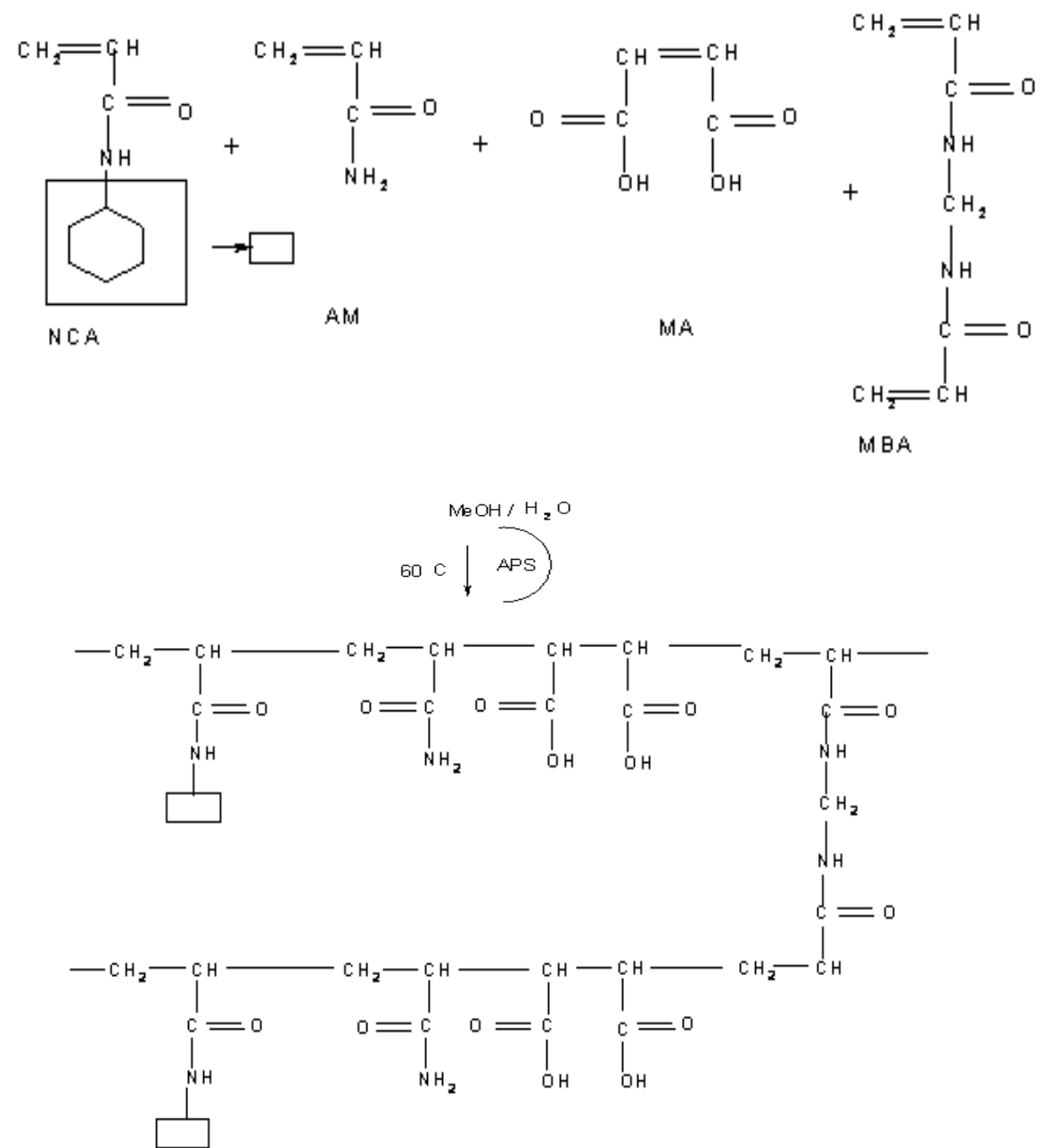

Figure -1 : Poly(N-cyclohexylacrylamide-co-Acrylamide/Maleic acid) Hydrogels 


\section{Spectral Characterization: FT-IR}

The FTIR spectrum of Poly (NCA-co-AM/MA ) Hydrogel is shown in Figure -2 . A broad peak corresponding to NH stretching of NCA was observed around $3294 \mathrm{~cm}^{-1}$. In addition to this, the peaks were also observed at $1651 \mathrm{~cm}^{-1}$ corresponding to $\mathrm{C}=\mathrm{O}$ of NCA and $\mathrm{C}=\mathrm{O}$ of carboxyl unit at $1534 \mathrm{~cm}^{-1}$ corresponding to $\mathrm{C}=\mathrm{ONH}_{2} \mathrm{AM}$ unit. The band at 2950 $\mathrm{cm}^{-1}$ is due to $\mathrm{C}-\mathrm{H}$ stretching of polymer backbone. The above IR analysis indicates the presence of all monomeric units in the crosslinked hydrogel.

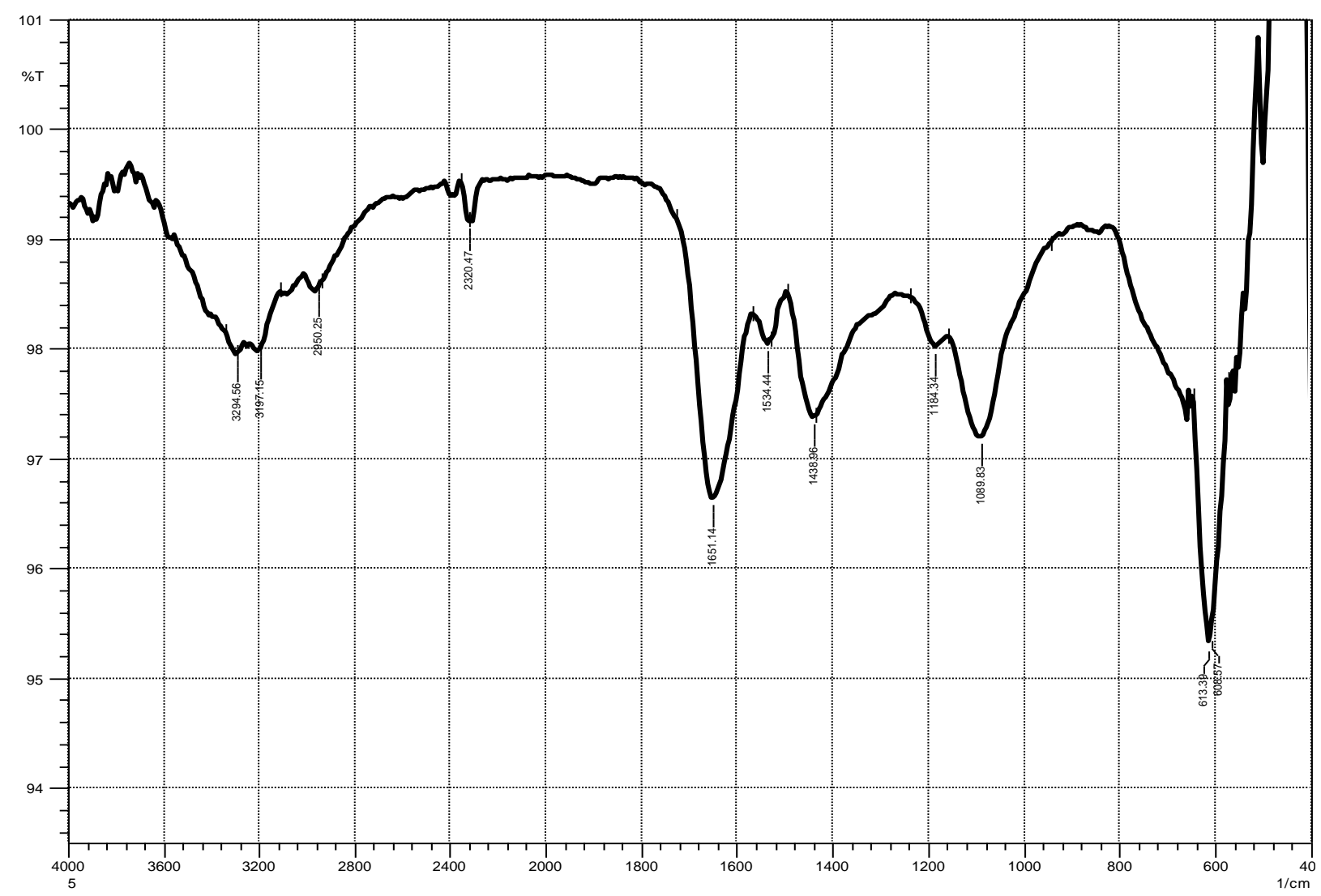

Figure - 2: FTIR spectrum of Poly (NCA-Co-AM/MA ) Hydrogel

\section{SEM Analysis}

SEM images of Poly (NCA-Co-AM/MA ) Hydrogel is given in Figure -3.The images indicate the hydrogels have more porous and well tye structure on the surface. $0.1 \mathrm{~g}$ of MA hydrogel has more porous on the surface and $0.3 \mathrm{~g}$ of MA containing deep wells on the surface. When the content of MA increases the size of the pores also increases. Therefore, $0.3 \mathrm{~g}$ of MA hydrogel absorb more amount of water than the $0.1 \mathrm{~g}$ of MA hydrogel. These materials may be used as biomaterials for medical purpose. 


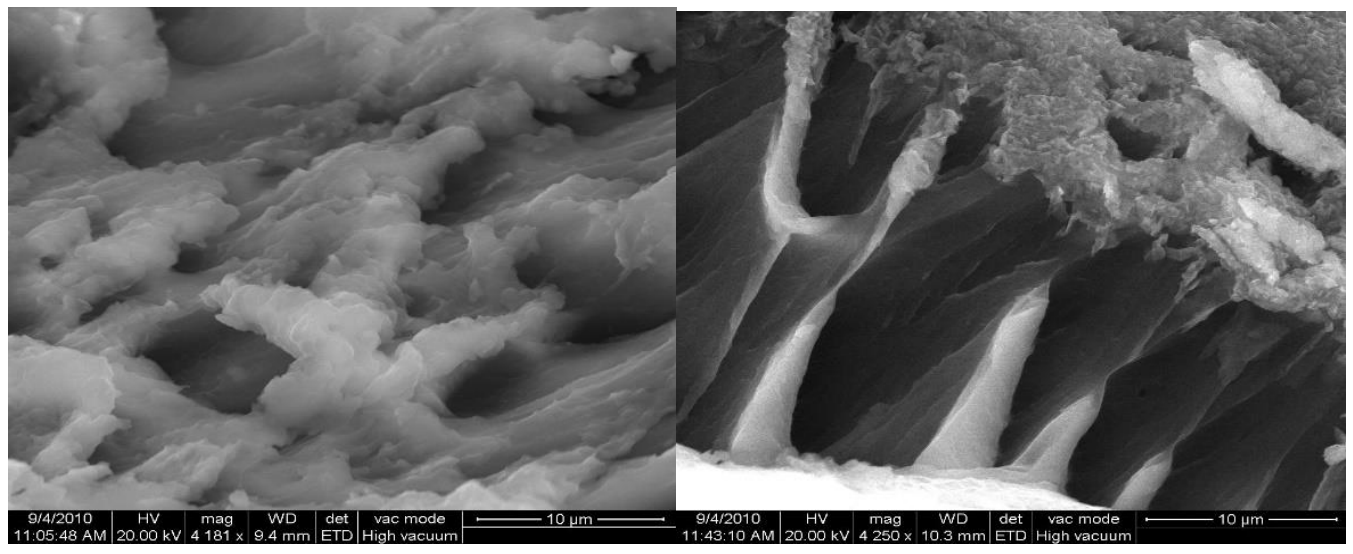

Figure-3: SEM images of Poly (NCA-Co-AM/MA ) Hydrogel

\section{XRD Studies}

The XRD patterns of Poly (NCA-co-AM/MA) are given in Figure -4 containing different content of MA. There are two different peeks, are observed at $2 \theta: 20 \& 42$ with different intensity. These peaks showed a peak broadening and it conform that the Hydrogels are more amorphous and less crystalline in nature. When the content of MA is $0.2 \mathrm{~g}$, the peak intensity also varies with more peak broadening. Therefore $0.2 \mathrm{~g}$ of MA containing Hydrogel is more amorphous then $0.1 \mathrm{~g}$ of MA containing Hydrogel. Also it conform that more the amorphous more will be the swelling [11-13].

(a)

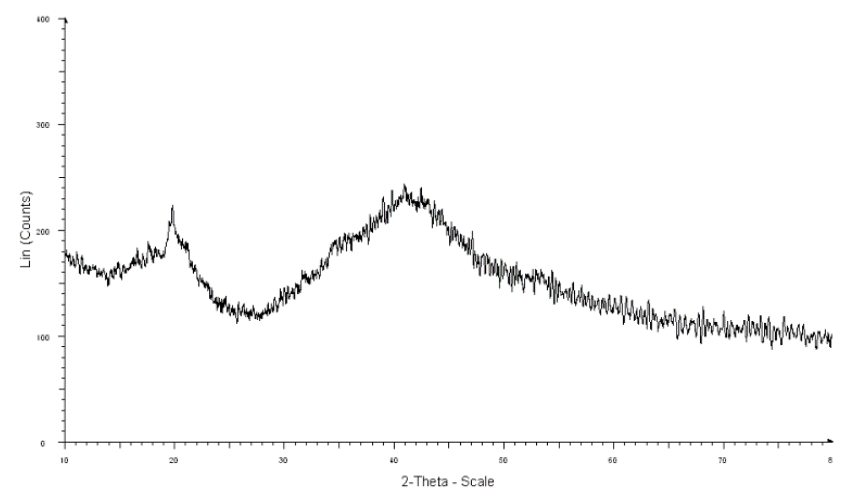

(b)

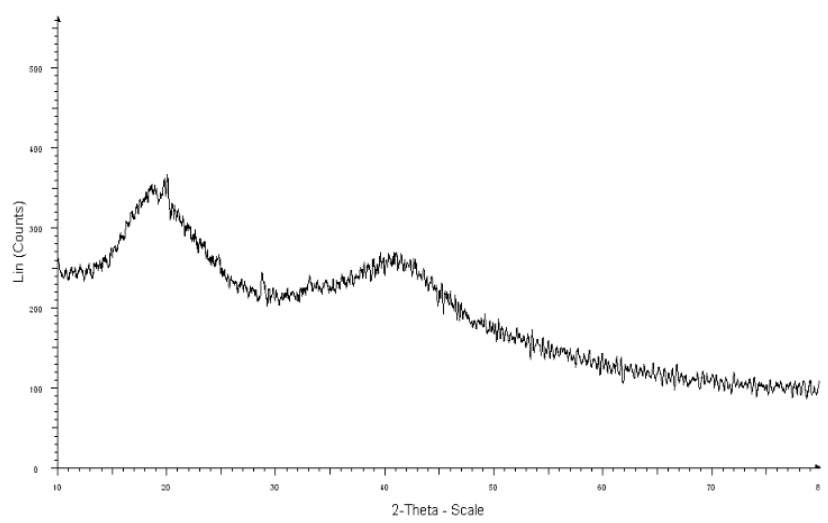

Figure -4: XRD patterns of Poly (NCA-co-AM/MA) Hydrogels (a) 0.1g (b) 0.2g of MA 


\section{TGA Studies}

The TGA thermograms of Poly (NCA-co-AM/MA) Hydrogels are given in Figure -5, and the stages of decomposition temperature and weight loss at various levels are shown in Table2. The initial weight loss of the Hydrogel containing $0.1 \mathrm{~g}$ and $0.2 \mathrm{~g}$ of MA are 14 and 12 respectively. The initial weight loss is due to the evaporation of free water and inter layered water present in the sample. The first stage and the second stage is attributed to the rupture of the Maleic acid main chain and the decomposition of crosslinker respectively. The third stage is due to the main chain scission in the polymer back bone. The residual weight is $12-16 \%$. From the data given in Table -2 , we can conclude that $0.2 \mathrm{~g}$ of MA containing Hydrogel is slightly more stable than the $0.1 \mathrm{~g}$ of MA containing hydrogel.

Table -2: Thermal behavior of Poly (NCA-co-AM/MA) Hydrogels

\begin{tabular}{|c|c|c|c|c|c|c|}
\hline \multirow[t]{2}{*}{ Hydrogels } & \multirow{2}{*}{$\begin{array}{c}\text { (IDT) } \\
\text { (Initial } \\
\text { weight loss } \\
\% \text { ) }\end{array}$} & \multicolumn{3}{|c|}{$\begin{array}{c}\text { Decomposition Temperature } \\
\left({ }^{0} \mathrm{C}\right) \\
(\% \quad \text { weight loss })\end{array}$} & \multirow[t]{2}{*}{$\begin{array}{c}\text { Residual } \\
\text { weight } \\
\%\end{array}$} & \multirow[t]{2}{*}{ (FDT) } \\
\hline & & Stage 1 & Stage 2 & Stage 3 & & \\
\hline $0.1 \mathrm{~g}$ of MA & $\begin{array}{l}150 \\
(14)\end{array}$ & $\begin{array}{l}220 \\
(14)\end{array}$ & $\begin{array}{l}330 \\
(15)\end{array}$ & $\begin{array}{l}410 \\
(45)\end{array}$ & 12 & 730 \\
\hline $0.2 \mathrm{~g}$ of $\mathrm{MA}$ & $\begin{array}{l}145 \\
(12)\end{array}$ & $\begin{array}{l}215 \\
(10)\end{array}$ & $\begin{array}{l}330 \\
(13)\end{array}$ & $\begin{array}{l}420 \\
(49)\end{array}$ & 16 & 780 \\
\hline
\end{tabular}

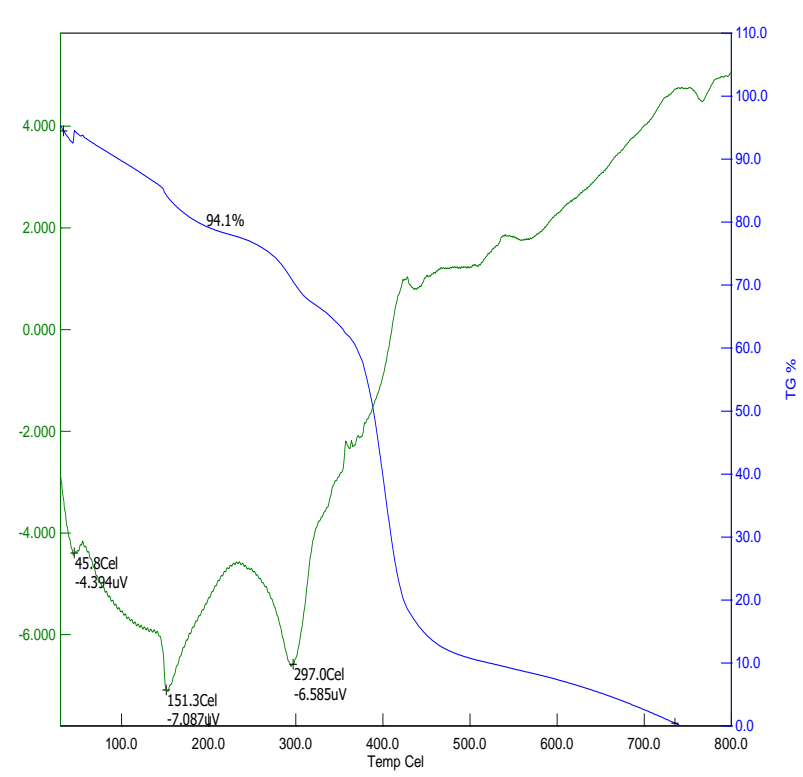

(a)

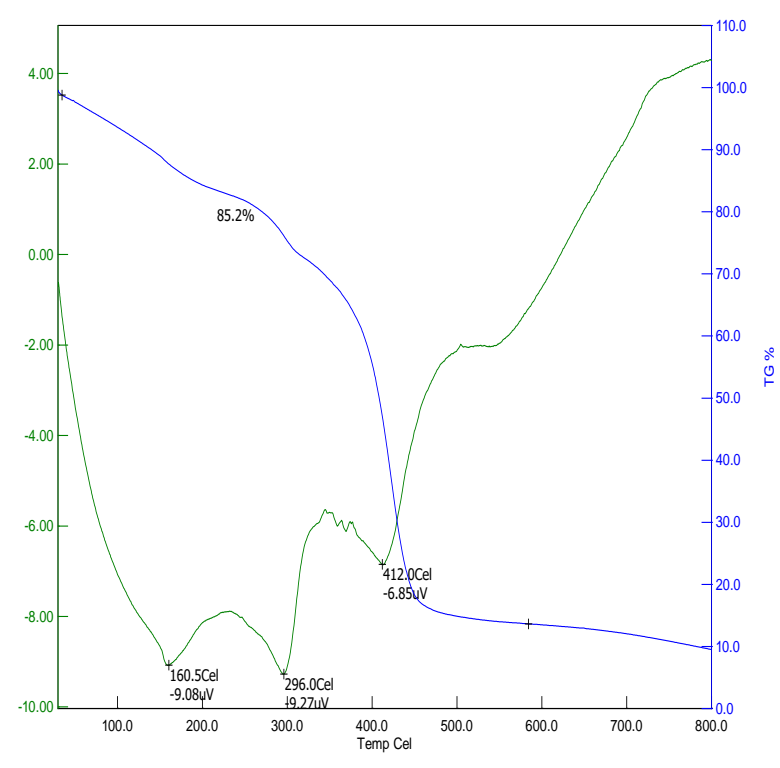

(b)

Figure -5:TGA curves of Poly (NCA-co-AM/MA) Hydrogels (a) 0.1g (b) 0.2g of MA 


\section{Swelling studies of Poly (NCA-co-AM/MA) Hydrogels in water and MB dye}

Equilibrium swelling ratio of Hydrogels in water with different feed contents MA is shown in Figure -6 (a). The swelling rate was slow during the first few minutes; it indicates that the initial swelling is due primarily to the water penetrating into the polymeric gel through capillary and diffusion. Then the penetrated water is absorbed by hydrophilic groups such as MA and AM through formation of hydrogen bonds. The swelling is driven by repulsion of hydrophilic groups inside the network and osmotic pressure difference between the gels and the external solution. The swelling rate is gradually increases until the equilibrium swelling is reached.

From the Figure -6 (a) , it is noticed that the extent of swelling of Hydrogels at equilibrium increases with an increase in the concentration of functional ionizable groups in the network. It is well that the swelling of hydrogel is induced by electrostatic repulsion of the ionic charges of its network. The ionic charges in the hydrogel network are important for swelling. $0.2 \mathrm{~g}$ of MA containing hydrogel has more charges then $0.1 \mathrm{~g}$ of MA containing Hydrogel. Therefore, higher content of ( $\mathrm{COO}^{-}$group) MA has higher swelling rate [14].

The equilibrium swelling ratio curves of Hydrogels in Methylene blue are given in Figure -6 (b). The swelling ratio of Hydrogels depends on the hydrophilicity of polymer chain and porous material and structure of hydrogel network. When the Poly(NCA-co-AM/MA) Hydrogel contact with water, water diffuses into it and causes swelling. The hetero atoms on the dye may form a complex with the water and hydroxyl group in them form hydrogen bonds that increased swelling behavior in Hydrogels.

(a)
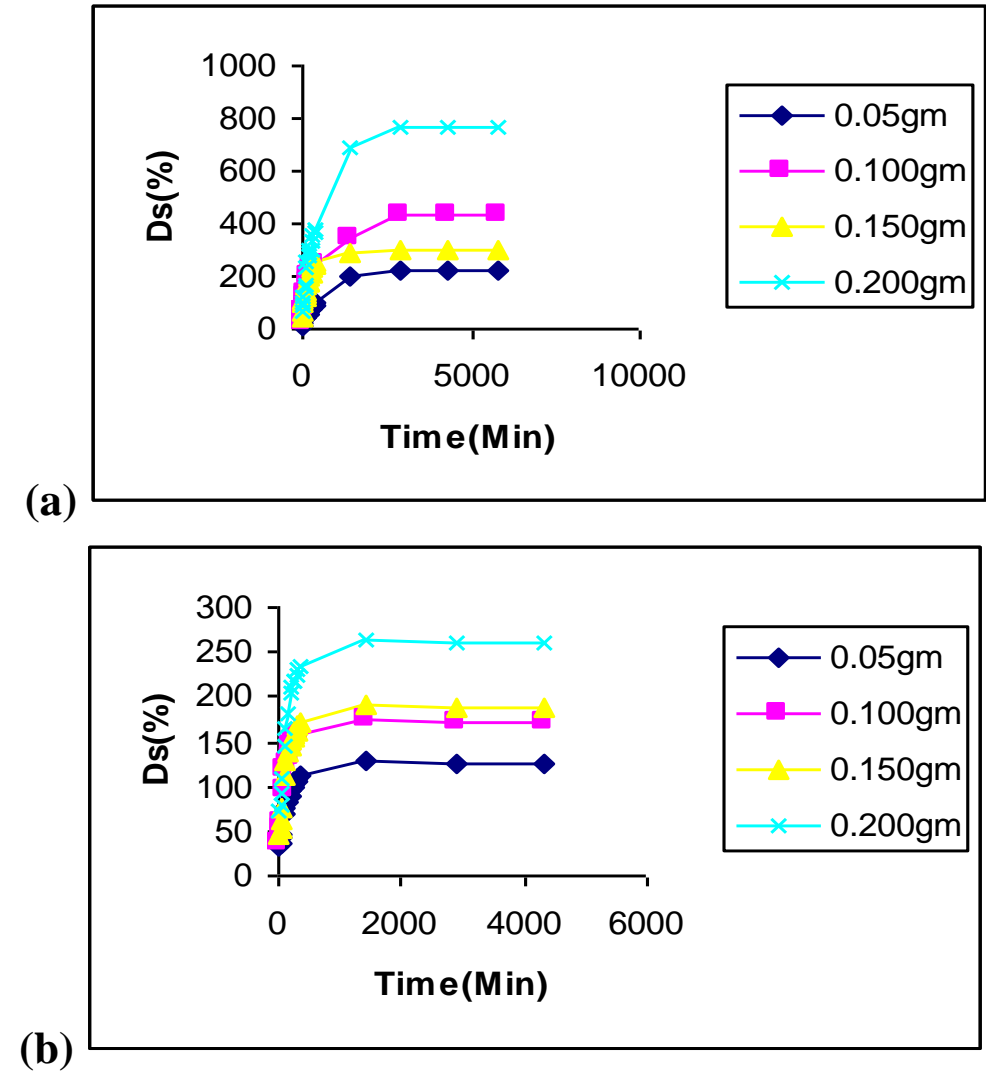

Figure -6: Swelling behavior of Poly (NCA-co-AM/MA)/Hydrogels in (a) Water (b) MB solution 


\section{Effect of Ionic Strength}

Swelling behavior of Poly (NCA-co-AM/MA) Hydrogel in different concentration of $\mathrm{NaCl}$ and $\mathrm{KCl}$ are given in Figure -7 .The Ds(\%) of the Poly(NCA-co-AM/MA) Hydrogel have been studied at different concentrations $(0.5,1,1.5,2,2.5 \%)$ of $\mathrm{NaCl}$ and $\mathrm{KCl}$. It was found that swelling decreases with increase in salt concentration. In water, the Hydrogel has maximum osmotic pressure, hence the maximum swelling. But when the Hydrogel was placed in $\mathrm{NaCl}$ and $\mathrm{KCl}$ solutions, the osmotic pressure of ionic hydrogel is lowered due to $\mathrm{Na}^{+}, \mathrm{K}^{+}$and $\mathrm{Cl}^{-}$ ions. This phenomenon was observed in the swelling of ionic hydrogels and attributed to a charge screening effect of the additional cations causing a non-perfect anion-anion electrostatic repulsion. It leads to a decrease in osmotic pressure difference between the Hydrogel network and the external solution $[15,16]$.
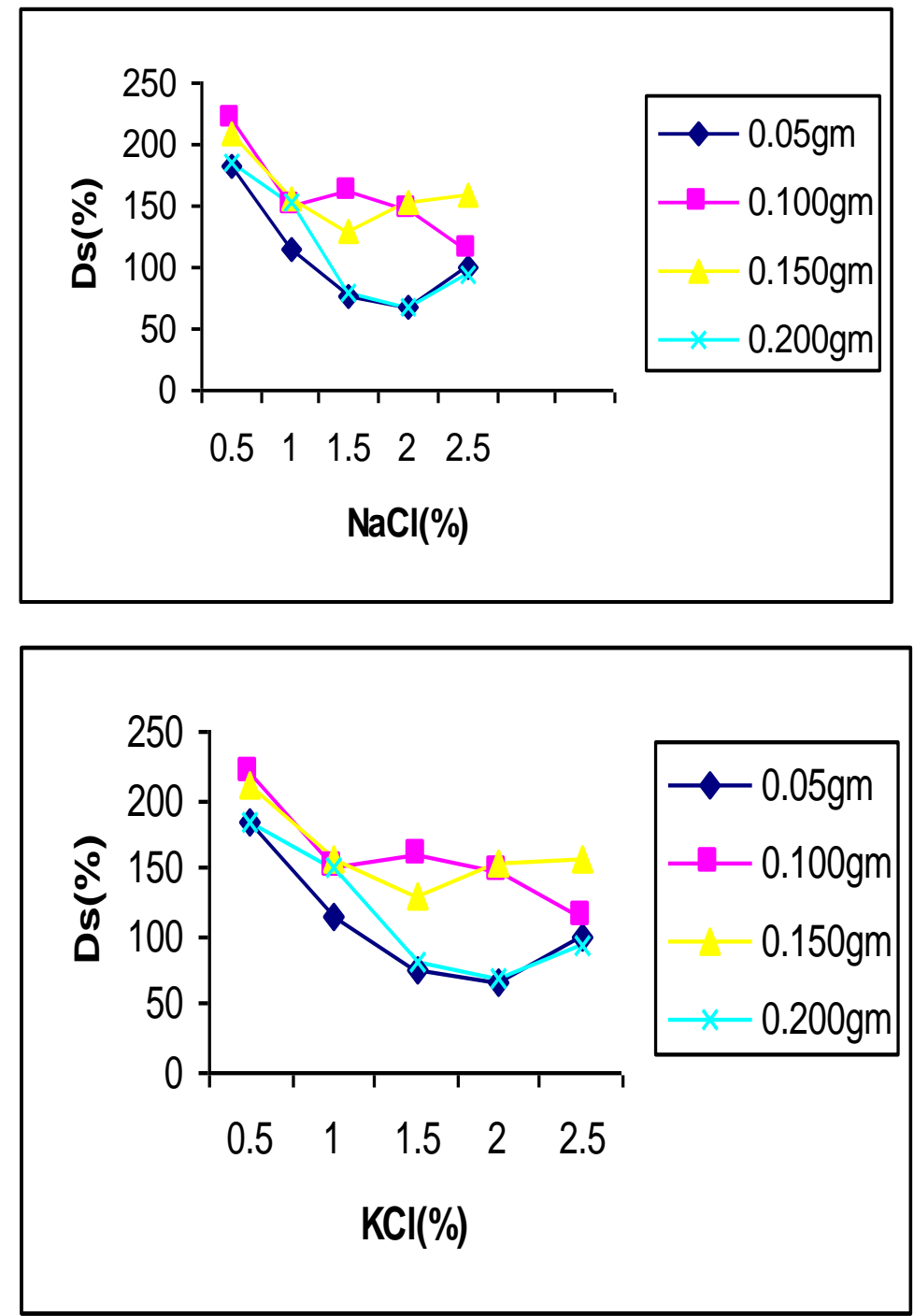

Figure -7: Swelling behavior of Poly (NCA-co-AM/MA) Hydrogels at different Concentrations of electrolytes $(\mathrm{NaCl}$ and $\mathrm{KCl})$

\section{Adsorption capacity (Q) and Removal efficiency (RE \%) of MB dye}

The adsorption curves of Hydrogels are shown in Figure- 8 and the values are indicated in Table-3. The maximum adsorption capacity is about 420.2 for $0.050 \mathrm{~g}$ of MA 402 for $0.100 \mathrm{~g}$ 
of MA, 434.5 for $0.150 \mathrm{~g}$ MA and 432.4 for $0.200 \mathrm{~g}$ of MA. After one day all Hydrogel showed dark color compared with the original composites. Also, the color of MB solution became colorless compared with the original solution. The cationic dyes like MB have electronegative atoms such as nitrogen and sulfur behave like hydrophilic groups and form hydrogen bonds with water. Thus, the swelling increased because the MB brings water into them [17]. The Dye removal efficiency of Hydrogel are given in Figure- 8 and Table-3.The maximum Removal efficiency is about 47.9 for $0.150 \mathrm{~g}$ of Maleic acid containing Hydrogel.

Table-3: Removal efficiency and Adsorption capacity of Poly (NCA-coAM/MA)Hydrogels

\begin{tabular}{|c|c|c|c|}
\hline S.No & $\begin{array}{c}\text { Weight of } \\
\text { MA(g) }\end{array}$ & RE (\%) & Q \\
\hline $\mathbf{1}$ & 0.050 & 41.9 & $\mathbf{1 8 8 . 7}$ \\
\hline $\mathbf{2}$ & 0.100 & 38.2 & $\mathbf{1 7 3 . 9}$ \\
\hline $\mathbf{3}$ & 0.150 & 47.9 & $\mathbf{1 7 9 . 0}$ \\
\hline $\mathbf{4}$ & $\mathbf{0 . 2 0 0}$ & $\mathbf{3 9 . 7}$ & $\mathbf{1 8 4 . 0}$ \\
\hline
\end{tabular}
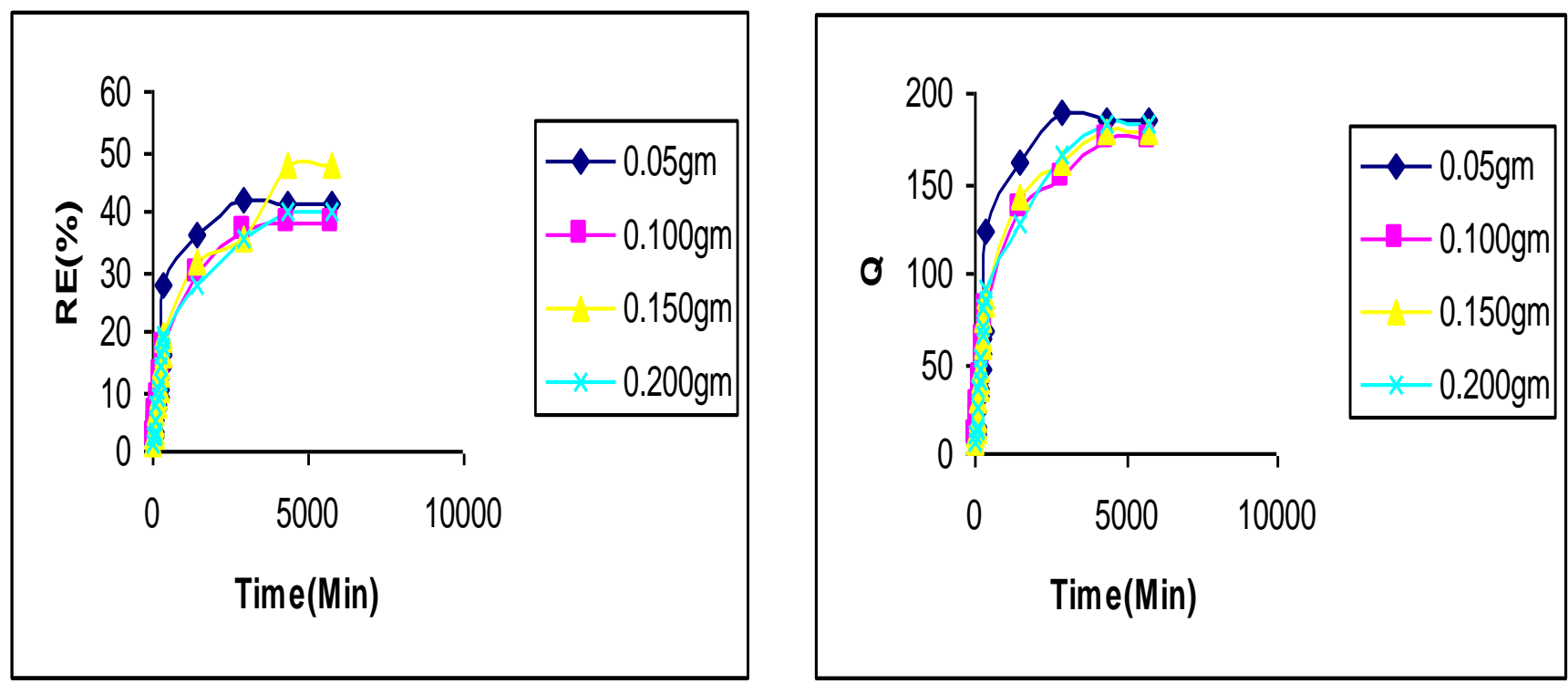

Figure-8: Removal efficiency and Adsorption capacity of Poly (NCA-co-AM/MA) Hydrogels 


\section{Conclusions}

we have synthesized poly (NCA-co-AM/MA) hydrogel with various Maleic acid content by free radical polymerization at $60^{\circ} \mathrm{C}$. FTIR confirmed the presence of monomeric units in the polymeric chain. The effect of two cationic salt solutions on the swelling was studied. The hydrogels showed up to $47.9 \%$ removal efficiency towards methylene blue dye adsorption study.Our synthesized hydrogels may be considered as good candidate for environmental application to retain more water and dye.

\section{References:}

1. N.Kashyap, N. Kumar and M. Kumar, Hydrogels for Pharmaceutical and Biomedical Applications, Critical Review in Therapeutic Drug Carrier Systems, (2005) 22,107-117.

2. D. Ma and L.M.Zhang , Journal of Physical Chemistry B, (2008)112, 20, 6315-6321.

3. Y. Mohan, T. Premkumar, K. Lee and K.E.Geckeler, Macromolecular Rapid Communications, (2006) 2716, 1346-1354.

4. R.Wang, J. Yang, Z. Zheng, M.D. Carducci, J. Jiao, and S.Seraphin Angewandte Chemie International Edition, (2001) 40,3, 549-552.

5. Y. Murali Mohan, T. Premkumar, K.J. Lee and K.E. Geckeler, Macromol Rapid Commun., ( 2006)27, 1346-1352.

6. C. Wang, N.T. Flynn and R. Langer, Adv. Mater. ,(2004)16, 1074-1080.

7. M.Y.Park, S. Lim and, S. E. Park, Macromol. Res. ,( 2009) 17, 307 -312.

8. X. Zhao, X. Ding, Z . Deng, Z. Zheng Y. Peng and X. Long, Macromol Rapid Commun. ,(2005) 26, 1784-185.

9. B.A.Brundha and P. Pazhanisamy, Int J Chemtech Res.,(2010) 2, 2191-2197

10 .P.Pazhanisamy and B.S.R.Reddy, Express Polymer Letters, (2007)1(11), 740-747 .

11.J.R.Patel, K.H.Patel and R.M .Patel, Colloid Polym. Sci., (2009) 287, 89-95.

12.M. Zendehdel, A.Barati and H. Alikhani, e-Polymers,no. 002 (2011).

13. Y.Ling and M.Lu, e-Polymers, 40 (2008).

14. S.Ekici, Y.Ișlkver and D.Saraydın, Polymer Bulletin ,(2006) 57(2), 231-241 .

15. H.Kasgoz, Polymer Bulletin , (2006) 56, 517-528.

16. D. Solpan, Z.Kolge and M.Torun, Journal of Macromolecular science,Part A:Pure and Applied Chemistry, (2006) 43, 129-152.

17. T.A. Paulino, M. G.Campese, L. S Favaroi, R. M.Guilherme, B. E.Tambourgi and E.Muniz, e-Polymers, 122 (2007). 